\title{
Does laparoscopic appendectomy increase the risk of intra- abdominal abscess in children who have perforated appendicitis?
}

\author{
Fatih Akbıyık$^{1} \odot$, Günay Ekberli ${ }^{1}$, Yusuf Hakan Çavuşoğlu² $\odot$ \\ ${ }^{I}$ Department of Pediatric Surgery, Ankara Children's Hematology and Oncology Training and Research Hospital, Ankara, Turkey \\ ${ }^{2}$ Department of Pediatric Surgery, Gazi University School of Medicine, Ankara, Turkey
}

DOI: $10.18621 /$ eurj.412177

\begin{abstract}
Objective: The aim of this study is to compare the rates of intraabdominal abscesses (IAAs), in laparoscopic appendectomy (LA) and open appendectomy (OA) for perforated appendicitis in children.

Methods: A retrospective database search of consecutive cases of children with a diagnosis of perforated appendicitis who underwent OA or LA by the first author or were operated under his supervision diagnosed with appendicitis between 2011 and 2014 and who underwent surgery as treatment was conducted.

Results: Seventy-eight patients were included in our study. Forty-two and 36 patients underwent LA and OA, respectively. One case was converted from LA to OA. There was no statistically significant difference at superficial incisional surgical-site infections and IAA between groups but drain placement ratio and length of hospital stay was higher in OA group.

Conclusions: The lack of difference in postoperative incidence of IAA supports the idea that LA does not increase the risk of IAA in perforated appendicitis. Although LA for perforated appendicitis in children has been intensely debated, our findings indicate that laparoscopic procedures performed by experienced pediatric surgeons will decrease the risk of complication and conversion to OA. Laparoscopy in children is a safe procedure for perforated, complicated appendicitis.
\end{abstract}

Keywords: appendicitis, abdominal abscess, laparoscopy, child

Received: April 3, 2018; Accepted: May 11, 2018; Published Online: August 13, 2018

\begin{abstract}
A ppendicitis is resulting from luminal obstruction and continuation of simple inflammation to perforation and subsequent abscess formation. Appendectomies are performed frequently in pediatric surgical practice. The use of laparoscopy by surgeons to manage appendicitis is increasing because laparoscopy offers the advantages of abdominal exploration associated with open procedures, along with decreased postoperative analgesic requirements, decreased
\end{abstract}

length of hospital stay, and better cosmetic results, partly because of the technical advances in terms of refinements in instruments and increased technical experience of surgeons with the technique [1-3]. However, there is an intense debate regarding the occurrence of intraabdominal abscesses (IAAs) after laparoscopy, especially in cases of complicated appendicitis [4-6].

The aim of this study is to compare the rates

Address for correspondence: Yusuf Hakan Çavuşoğlu, MD., Professor, Gazi University School of Medicine, Department of Pediatric Surgery, Ankara, Turkey

E-mail:hakancavusoglu@hotmail.com 
of IAA, i.e., surgical-site infections (SSIs), in laparoscopic appendectomy (LA) and open appendectomy (OA) for perforated appendicitis in children.

\section{METHODS}

Using the hospital information system at Ankara Children's Hematology Oncology Training and Research Hospital, Department of Pediatric Surgery, we conducted a retrospective database search of consecutive cases of children diagnosed with appendicitis between January 2011 and December 2014 and who underwent surgery as treatment.

Patients with a diagnosis of perforated appendicitis who underwent OA or LA by the first author (F.A.) or were operated under his supervision were included in this study. Ankara Children's Hematology Oncology Education and Research Hospital is a high-circulation training hospital that accepts patients not covered by health insurance as well. A total of five pediatric surgery specialists work at the pediatric surgery clinic.

The following patients were included in the study: those with a surgical diagnosis of perforated appendicitis in the operative records (intraoperative presence of appendiceal perforation and/or localized or generalized peritonitis or periappendiceal abscess); those without a surgical diagnosis but with a histopathological result of perforated appendicitis. We excluded cases of interval, non-perforated, and incidental appendectomy. There were no missing data. The patients' demographic and clinical data, operation type, LA to OA conversion status, length of hospital stay, histopathology reports, and postoperative complications were evaluated.

\section{Operative Technique}

Hospitalized children were allowed nothing by mouth and received intravenous hydration. Operations were performed when operating rooms were available. The patients underwent either LA or OA. OA was performed whenthe surgeon suspected severe intraabdominal adhesions or when a laparoscopy set was not available.

LA was performed with the "in" LA technique that uses three ports. An infraumbilical 10-mm camera port, two 5-mm working ports atthe suprapubic and left-lower quadrants, and a $30^{\circ} 5$-mm telescope were used. The mesoappendix was dissected using a bipolar vascular sealing device (Valleylab LigaSure, USA) or monopolar hook cautery, and the appendiceal stump was secured with polymer clips (Hem-o-lock ${ }^{\circledR}$ Weck, USA). The specimen was removed through the 10-mm port with or without a 5-mm laparoscopic bag, depending on the specimen size. The operative field was irrigated with $25-50 \mathrm{~mL}$ of physiological saline solution. Paracolic, pelvic, perihepatic, and splenic regions were checked and all existing purulent material was aspirated. In the presence of intensive purulent material, a $1 / 4$ " Penrose drain catheter was placed through the 5-mm suprapubic port.

OA was performed through aright-lower quadrant transverse or paramedian incision. After the appendix, has been removed, all purulent material in the abdominal cavity was aspirated. The operative field and the fields with purulent material were wiped with saline-soaked gauze, performed. A 1/4" Penrose drain catheter was placed through a separate incision when copious purulent material was present.

\section{Postoperative Care}

All patients who underwent appendectomy received a triple-antibiotic regimen (ampicillin/penicillin + amikacin + ornidazole, in appropriate therapeutic dosages) intravenously before the skin incision. The regimen was continued until discharge. Nasogastric decompression was used only when required. All wounds underwent primary closure. Drains were removed before discharge. Antibiotics were continued after dischargeonly if the patients had SSIs.

The infectious complications were diagnosed according to criteria for defining a SSI in the Guidelines for Prevention of Surgical Site Infections, 1999 [7]. IAA was treated conservatively by wide spectrum parenteral antibiotics.

\section{Statistical analysis}

Statistical analyses were made with SPSS version 18.0 (SPSS Inc., Chicago, IL, USA). The distribution of continuous variables was evaluated using the onesample Kolmogorov-Smirnov test. Mean \pm standard deviations were used for presenting normally distributed data, whereas median and ranges were used for presenting non-normally distributed data. Two averages for constant variables were compared using 
the t-test for normally distributed data and the MannWhitney U-test for non-normally distributed data.Categorical variables were analyzed using the chi-square test and Fisher's exact test when required. A $p$ value of $<0.05$ was considered significant.

\section{RESULTS}

A total of 1793 patients underwent surgery between 2011 and 2014. Of these, 215 were diagnosed with perforated appendicitis. The first author performed or supervised surgery on 78 of these patients, and these were included in our study. Fortytwo and 36 patients underwent LA and OA, respectively. One case was converted from LA to OA. Patients had a mean age of $9.5 \pm 4.2$ (range; $2-18$ years) and $10.0 \pm 3.8$ (range; $2-18$ years) years in the LA and OA groups, respectively. The age difference between groups was not statistically significant $(p=$ 0.530). Demographic data and patient characteristics are presented in Table 1.

One case was converted from LA to OA because of difficult dissection. There were no intraoperative complications or deaths in either group.

There was no statistically significant difference in the rates of superficial incisional SSI and IAA between groups but drain placement ratio and length of hospital stay was higher in the OA group (Table 1). There was a urinary tract infection at LA group as postoperative complication other than SSI. There were no other pathologies except appendicitis at histopathology reports. The mean follow-up period was $3.6 \pm 1.7$ months.

\section{DISCUSSION}

LA has the following advantages: less postoperative pain, decreased length of hospital stay, and better cosmetic results. In addition, it allows the surgeon to perform a whole-abdomen examination and pelvic examination in girls $[1,2]$. These advantages increased the frequency at which laparoscopic surgeries have been performed for the treatment of appendicitis in children. Cheong et al. [3] reported increased LA rates from $28.8 \%$ to $66.4 \%$ between 2004 and 2010 in Canada. Although Lin et al. [4] noted that althoughthe LA rates for perforated appendicitis have increased from $9.9 \%$ in 1999 to $46.6 \%$ in 2007 in the United States, there is still debate about performing laparoscopy in complicated appendicitis.

The subject discussed most frequently by investigators who object to LA for perforated appendicitis is IAA. Gupta et al. [5] argued that using too much irrigation fluid and aggressive manipulation of the infected appendix increased the incidence of

Table 1. Characteristics of patients who underwent laparoscopic versus open appendectomy

\begin{tabular}{lccc}
\hline & $\begin{array}{c}\text { Laparoscopic Appendectomy } \\
(\mathbf{n = 4 2})\end{array}$ & $\begin{array}{c}\text { Open Appendectomy } \\
(\mathbf{n}=\mathbf{3 6})\end{array}$ & $\boldsymbol{p}$ \\
\hline Age (range), years & $9.5 \pm 4.2(2-18)$ & $10.0 \pm 3.8(2-18)$ & $0.530^{*}$ \\
Male/Female & $24 / 18$ & $26 / 10$ & $0.166^{* *}$ \\
Operative time (min) & $39.3 \pm 12.6$ & $41.5 \pm 9.6$ & $0.381^{*}$ \\
Drain placement & $3(7.1 \%)$ & $10(27.8 \%)$ & $\mathbf{0 . 0 1 5 ^ { * * }}$ \\
Removing time of drain (days) & $2.7 \pm 1.5$ & $3.6 \pm 2.6$ & $0.577^{*}$ \\
Superficial Incisional SSI & $2(4.8 \%)$ & $4(11.1 \%)$ & $0.267^{* * *}$ \\
IAA & $2(4.8 \%)$ & $1(2.8 \%)$ & $0.558^{* * *}$ \\
Length of stay (range), days & $3.2 \pm 1.3(2-8)$ & $4.4 \pm 2.6(3-15)$ & $\mathbf{0 . 0 1 8 ^ { * }}$ \\
\hline
\end{tabular}

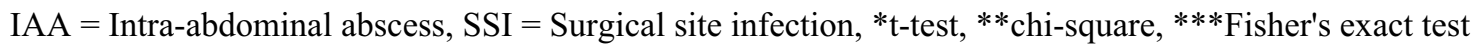


IAA. Memon et al. [6] argues that pneumoperitoneum created by carbondioxide increased bacterial translocation. Moore et al. [8] reported in a study recently done that IAA rates increased if irrigation was done in LA. Another study found that irrigation did not change the ratio of abscess, but it prolonged operation time [9]. The authors of the current study tended to avoid intense irrigation, and they used irrigation only for hemostasis in the operative field. The purulent material is aspirated in LA and OA, and the abdominal cavity is wiped with wet sponge gauze in OA. Some authors such as Pokala et al. [10] argued that IAAs, which have never been observed in OA, occurred in $14 \%$ of LA cases. Moreover, Paik et al. [11] argued that LA was inconvenient in complicated appendicitis. Recently, Ferranti et al. [12] compared the LA and OA techniques for perforated appendicitis in a study on adults, and observed that IAA was found in $16.6 \%$ and $5 \%$ of LA and OA cases, respectively, difference between the groups was not statistically significant and he suggested that laparoscopic approach is a safe procedure for the treatment of uncomplicated appendicitis, but LA should be used with caution, or even avoided, in the cases of perforated appendicitis. Esposito et al. [13] reported that there was no difference in terms of formation of abscess between both techniques in a meta-analysis of 26 studies in children, which included over 1,00,000 cases. According to an analysis of results from more than one hundred thousand cases, Markar et al. [14] reported that although LA decreased the overall morbidity, it increased the risk of IAA. Chang et al. [15] found in a study done on children that the rates of IAA is 3\% in LA and $2 \%$ in OA. In our study, the difference in IAA rates were not significant as in this analysis.

Li et al. [16] mentioned that as the surgeons became more experienced, they did more complicated operations laparoscopically, which might have increased complications and conversion rates[16]. Akkoyun et al. [17] and Narci et al. [18] have concluded that irrigation and drainage were not necessary. The authors of the current study did not use drainage cathetersin cases of perforated appendicitis. In this study, drainage catheters were used in three patients (3/42) in LA and 10 patients (10/36) in OA. The lack of difference in postoperative incidence of IAA supports the idea that laparoscopy provides better aspiration of purulent material.

\section{CONCLUSION}

Although LA for perforated appendicitis in children has been intensely debated, our findings indicate that laparoscopic proceduresperformed by experienced pediatric surgeons will decrease the risk of complication and conversion to OA. Laparoscopy in children is a safe procedure for perforated, complicated appendicitis.

\section{Authors' Contributions}

F.A: Study conception and design, acquisition of data, analysis and interpretation of data, drafting of manuscript, critical revision; G.E: Acquisition of data, analysis and interpretation of data, drafting of manuscript; Y.H.Ç: Study conception and design, analysis and interpretation of data, drafting of manuscript, critical revision.

\section{Conflict of interest}

The authors disclosed no conflict of interest during the preparation or publication of this manuscript.

\section{Financing}

The authors disclosed that they did not receive any grant during conduction or writing of this study.

\section{REFERENCES}

[1] Guller U, Anstrom KJ, Holman WL, Allman RM, Sansom M, Peterson ED. Outcomes of early extubation after bypass surgery in the elderly. Ann Thorac Surg 2004;77:781-8.

[2] Croce E, Olmi S, Bertolini A, Magnone S. Laparoscopic surgery of pancreatic cancer: state of the art. Hepatogastroenterology 2005;52:1889-94.

[3] Cheong LH, Emil S. Pediatric laparoscopic appendectomy: a population-based study of trends, associations, and outcomes. J Pediatr Surg 2014;49:1714-8.

[4] Lin HF, Lai HS, Lai IR. Laparoscopic treatment of perforated appendicitis. World J Gastroenterol 2014;20:14338-47.

[5] Gupta R, Sample C, Bamehriz F, Birch DW. Infectious complications following laparoscopic appendectomy. Can J Surg 2006;49:397-400.

[6] Memon MA, Fitztgibbons RJ, Jr. The role of minimal access surgery in the acute abdomen. Surg Clin North Am 1997;77:1333-53.

[7] Mangram AJ, Horan TC, Pearson ML, Silver LC, Jarvis WR. 
Guideline for prevention of surgical site infection, 1999. Hospital Infection Control Practices Advisory Committee. Infect Control Hosp Epidemiol 1999;20:250-78; quiz 79-80.

[8] Denning DW, Park S, Lass-Florl C, Fraczek MG, Kirwan M, Gore R, et al. High-frequency triazole resistance found In nonculturable Aspergillus fumigatus from lungs of patients with chronic fungal disease. Clin Infect Dis 2011;52:1123-9.

[9] Adibe OO, St Peter SD. Equipoise, ethics, and the necessity of randomized trials in surgery. Arch Surg 2012;147:899-900.

[10] Pokala N, Sadhasivam S, Kiran RP, Parithivel V. Complicated appendicitis--is the laparoscopic approach appropriate? A comparative study with the open approach: outcome in a community hospital setting. Am Surg 2007;73:73741; discussion 41-2.

[11] Paik PS, Towson JA, Anthone GJ, Ortega AE, Simons AJ, Beart RW, Jr. Intra-abdominal abscesses following laparoscopic and open appendectomies. J Gastrointest Surg 1997;1:188-92; discussion 92-3.

[12] Siani LM, Ferranti F, De Carlo A, Quintiliani A. Completely laparoscopic versus open total gastrectomy in stage I-III/C gastric cancer: safety, efficacy and five-year oncologic outcome. Minerva Chir 2012;67:319-26.
[13] Caputo I, Secondo A, Lepretti M, Paolella G, Auricchio S, Barone MV, et al. Gliadin peptides induce tissue transglutaminase activation and ER-stress through $\mathrm{Ca} 2+$ mobilization in Caco-2 cells. PLoS One 2012;7:e45209.

[14] Markar SR, Koehler R, Low DE, Ross A. Novel multimodality endoscopic closure of postoperative esophageal fistula. Int J Surg Case Rep 2012;3:577-9.

[15] Chang HK, Han SJ, Choi SH, Oh JT. Feasibility of a laparoscopic approach for generalized peritonitis from perforated appendicitis in children. Yonsei Med J 2013;54:1478-83.

[16] Li X, Zhang J, Sang L, Zhang W, Chu Z, Li X, et al. Laparoscopic versus conventional appendectomy--a metaanalysis of randomized controlled trials. BMC Gastroenterol 2010;10:129.

[17] Akkoyun I, Tuna AT. Advantages of abandoning abdominal cavity irrigation and drainage in operations performed on children with perforated appendicitis. J Pediatr Surg 2012;47:1886-90.

[18] Narci A, Karaman I, Karaman A, Erdogan D, Cavusoglu $\mathrm{YH}$, Aslan $\mathrm{MK}$, et al. Is peritoneal drainage necessary in childhood perforated appendicitis?--a comparative study. J Pediatr Surg 2007;42:1864-8. 